\section{Research Square}

Preprints are preliminary reports that have not undergone peer review.

They should not be considered conclusive, used to inform clinical practice, or referenced by the media as validated information.

\title{
Pneumococcal Diseases Caused by Serotype Replacement in Colombia: A Cost-Effectiveness Analysis of Pneumococcal Conjugate Vaccines in Infants and Its Herd Protection in Older Adults
}

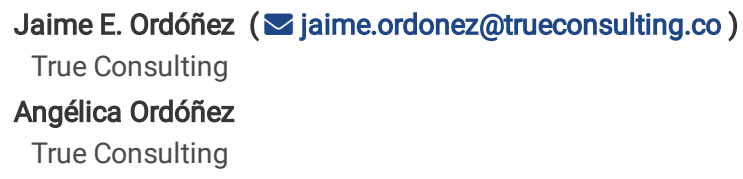




\section{Abstract}

Background. The recent and available evidence on the distribution of pneumococcal serotypes, which affects the effectiveness of pneumococcal conjugate vaccines (PCV), suggest that additional health economic studies will be important for better understanding of potential economic benefits of pneumococcal vaccination.

Methods A cohort simulation model was used for new births in Colombia between 2019-2022 and adults over 65 years, from social perspective (direct and indirect costs). The time horizon was a life expectancy and discount rate for costs and benefits of $5 \%$. The outcomes were presented in terms of avoided pneumococcal diseases - Invasive Pneumococcal Disease (IPD), Community Acquired Pneumonia (CAP), Acute Otitis Media (AOM), and sequelae-, years of life gained (AVG) and herd effect in older adults.

Results. Based on data from National Data of the serotype distribution between 2017-2019, PCV10 covers 5\% of serotypes while PCV13 $63 \%$. The additional cases that PCV13 would prevent are in children: 1,205 cases of IPD, 60,274 of CAP, 26,619 of AOM, 3,980 deaths, 28 cases of neuromotor disability and 1,251 cochlear implants. In older adults, PCV13 would prevent 818 additional cases of IPD and 29,983 of CAP, generating 149,186 additional LYGs to those of PCV10 with a saving to the health system and patients of US $\$ 169,261$ thousand. The model shows robustness in the sensibility analysis.

Conclusion. PCV13 is a cost-saving strategy versus PCV10 to prevent pneumococcal diseases.

\section{Background}

Pneumococcal diseases are caused by Streptococcus pneumoniae (S. pneumoniae), also known as pneumococcus. (1) The infection can result in a variety of infection-types: pneumonia, infection in the blood (bacteremia or sepsis), infection of the middle ear (acute otitis media - AOM) or bacterial meningitis. Although most pneumococcal infections are mild, they can sometimes be lethal or produce serious sequelae, such as brain damage or hearing loss. This invasive pneumococcal disease (IPD) is less frequent but more severe infection within pneumococcal diseases (2), where young children and the elderly are associated to present this disease with high case fatality ratio. (3)

Invasive meningitis, within of IPD, is the most lethal in toddler, about 1 in every 15 children under 5 years of age who suffer from pneumococcal meningitis die from this cause (1) and others remain with long-term problems, such as hearing loss or delayed neuromotor development (4); and highly lethal in older adults (5). Likewise, the case fatality rate for those with pneumonia complicated by bacteremia is approximately $20 \%$, and their lethality increases in older adults (6).

Unlike of IPD, the non-IPD are less severe but more common infection, occur outside of major organs such as the circulatory system or the central nervous system (CNS). The pneumococcus spreads from the nasopharynx (nose and throat) to the upper and lower respiratory system which can result in AOM or pneumonia (7). The lethality of pneumococcal pneumonia in the general population is $5 \%$ (8), whereas AOM infections are mild, are the most common form of pneumococcal disease (1), some children who develop recurrent infections may need ear tubs (9).

According to the World Health Organization (WHO), given that pneumococcal infection is a vaccine-preventable disease that causes more deaths in infants and children under five years (10), it recommends the use of conjugate vaccines in this condition (11). In 2007, the Ministry of Health included pneumococcal conjugate 7-valent vaccine (PCV7) in the National Immunization Plan (PAl, acronym in Spanish) of Colombia. Economic studies from the Pan American Health Organization (PAHO) and Fedesarrollo (a non-profit Colombian entity, dedicated to research on economic and social policy issues) concluded that vaccinating with PCV7 was a cost-saving strategy compared with not vaccinating $(12,13)$. The coverage of vaccinated population increased subsequently and gradually in the next years of its implementation. In September 2011, the PAl changed to pneumococcal 10-valent conjugated vaccine (PCV10) based on a cost-effectiveness analysis that concluded that routine vaccination with this health technology for S. pneumoniae in Colombia would save more cost as its prevention of AOM by all causes, although pneumococcal 13-valent conjugated vaccine (PCV13) would prevent more disease and deaths with a higher life years gained (LYG) (4).

After 8 years, since the introduction of PCV10, one of the most noticeable changes have been the redistribution of serotypes, which highlights the decrease in the contents in PCV10 and the significant increase in serotype 19A, which is not included in the vaccine. In fact, serotype 19A has presented major relevance in last year's according to Sistema de Redes de Vigilancia de Agentes Bacterianos Causantes de Meningitis y Neumonías (SIREVA II) reports (14, 15). Furthermore, invasive and non-invasive pneumococcal diseases in Colombia continue to generate a remarkable burden for the child population, despite the reduction in the number of cases of AOM in children under 5 years of age after the implementation of PCV10. (16)

Recently a cost effectiveness model was published evaluating economic impact of switch to PCV13 versus continue PCV10 in Colombia children under epidemiological scenario in 2014 (17) and of clinical trial published in the same year (18). It showed that switch-to PCV13 was a good value for money and prevent additional burden of pneumococcal disease saving additional treatment cost. Similarly The WHO stating that PCV13 may have an additional benefit in settings where disease attributable to serotype 19A or serotype 6C is significant (19).

Taking all these factors into account, having changes in serotype dynamics, costs of the vaccines, as well as the incidence of pneumococcal disease, it is necessary to continually reassess economic evaluations for this type of programs, in such a way that it allows decision makers to identify the most costeffective strategy given the current scenarios of these disease incorporating the direct and indirect benefits that the different alternatives may have. For that reason, the aim of this study is to estimate the value of PCV13 for the Colombian health system versus PCV10, by means of a cost-effectiveness 
analysis that allows to determine the incremental cost-effectiveness ratio, both in the prevention of IPD in terms of LYG as in pneumococcal pneumonia and AOM in terms of avoided cases in children under five years old between 2019 and 2022, as well as the herd effect in adults, expressed in terms of cases and deaths prevented by pneumococcal diseases.

\section{Methods}

\section{Target population}

Neonates projected to be born in Colombia between 2019 and 2022, who will be vaccinated, and adults older than 18 in the country or who turn 18 between 2019 and 2022, in which the herd effect will be evaluated.

\section{Comparators}

The strategies evaluated are the two pneumococcal conjugate vaccines that currently licensed in the scheme 2+1: PCV13 and PCV10. The first one is produced by Pfizer® and contains thirteen serotypes of pneumococcus $(1,3,4,5,6 \mathrm{~A}, 6 \mathrm{~B}, 7 \mathrm{~F}, 9 \mathrm{~V}, 14,18 \mathrm{C}, 19 \mathrm{~A}, 19 \mathrm{~F}$ and $23 \mathrm{~F})$ which are conjugated to the CRM197 protein of diphtheria as a carrier protein. The other vaccine, PCV10, developed by Glaxo Smith-Kline ${ }^{\circledR}$, differs from PCV13 does not contain the serotypes 3,6A and 19A and the carrier protein is protein D from non-typeable Haemophilus influenzae (PD) (NTHi), Tetanus Toxoid (TT), Diphtheria Toxoid (DT).

The Serum Institute of India Pvt. Ltd.'s PCV candidate (SIIPL-PCV), pre-qualified by WHO and with immunogenicity data (20), was not included in the analysis, due to the lack efficacy trial, it is not approved by National Institute for Surveillance on Drugs an Foods (INVIMA - Spanish acronym), and the price of this vaccine is not available, taking in consideration that for the national program, the purchase of vaccines from producer is via tender, the PAHO.

\section{Time horizon}

The relevant impact on public health of pneumococcal conjugate vaccines (PCVs) has been their high clinical efficacy, but also their protective effect during lifetime, for this reason, the time horizon for this cost-effectiveness analysis was the life expectancy.

\section{Study perspective}

This analysis has a social perspective, this implies identifying direct costs of resources associated with the use of these technologies and pneumococcal diseases treatment' costs and their aftermath, included or not in the Plan of Benefits of Health of Colombia (21). In the same way, indirect costs by loss of productivity in people with neurological sequelae caused by pneumococcal meningitis; and the health outcomes perceived by patients.

\section{Discount rate}

A discount rate of $5 \%$ was used for both costs and benefits. This is considered the discount rate that best fits the Colombian context and is also the discount rate recommended by the Institute of Technological Evaluation in Health in Colombia (22).

\section{Choice of health outcomes}

Outcomes were avoided cases of IPD (pneumococcal invasive pneumonia, pneumococcal sepsis and meningitis); community-acquired pneumonia (CAP), deaths by IPD, both children and adults; and pneumococcal AOM in infants. Similarly, sequels derived from pneumococcal disease such as neuromotor disability and cochlear implants; and LYG in children and adults. Prevented deaths and IPD cases in unvaccinated adults were estimated from herd effect in this population (23).

\section{Clinical parameters}

A search strategy was carried out to identify clinical efficacy of pneumococcal vaccines, including only phase III and IV randomized controlled trials (RCTs) in infants, and excluding those that have included polysaccharide vaccine. Finally, we looked for RCTs that met the Grading of Recommendations Assessment, Development and Evaluation (GRADE) bias control criteria (24). The effectiveness was adjusted for the national distribution of pneumococcal serotypes in Colombia between 2017 and 2019 (66\% PCV13 and 5\% PCV10), based on the information reported in SIREVA II (14,15). These is the most commonly used approach to calculate the direct effect of each vaccine (25).

The vaccination coverage was $89 \%$ in each birth cohort (26), which in turn was adjusted among infants as a herd effect in this group (27), $93.6 \%$. Also during this time the adults will be at risk of invasive pneumococcal disease, herd immunity is accounted in the model as $22.14 \%$ (28), and serotypes coverage in this group was adjusted (14) (Table 1).

For children above 5 years old, the bacterial CAP, and pneumococcal AOM were taken from control arm in the RCT of PCV10 (18) and observational studies. The incidence and lethality of meningitis due to S. pneumoniae were estimated from average in the reports from 2017 - 2019 years from Health National Institute. The incidence of sepsis due to S. pneumoniae was estimated from Colombian Health Services Delivery Records (RIPS) and the proportion of cases by S. pneumoniae reported in epidemiological studies. For the rest age groups the incidence rates were derived from RIPS during vaccinal period with PCV10. The mortality for all the causes was implemented an age-dependent according with the Colombia's National Administrative Department of Statistics (DANE) (31) (Table 2). 
Costs were calculated in Colombian pesos (COP) and later were converted into USD, based on an average exchange rate reported from the Central Colombian Bank on 2019, COP 3,281 for USD 1 (38).

\section{Estimating resources and costs}

A top-down methodology to calculate costs of hospital care for children with IPD and bacterial CAP, the outpatient healthcare for children with neuromotor disability, and the adults with IPD was made, by mean a search of individual costs of all interventions, procedures and medicines required from the database of a Health Maintenance Organization (HMO) of Colombia with national presence and costs. A bottom-up methodology for calculation costs of outpatient treatment in children with pneumococcal AOM and adults with CAP was made, taken the costs from taken the costs from the Drug Price Information System (SISMED, acronym in Spanish) (39). Cochlear implant total costs for the treatment of profound sensorineural hearing loss in children were taken from an economic analysis published in Colombia in 2012 (40), and the costs were adjusted for the year 2019 based on the accumulated consumer-price index for the period 2012-2019 (Table 3).

Direct costs of healthcare for children with neuromotor disability were calculated at American dollars (USD) \$ 294.14 per year, including outpatient healthcare by medical specialists, physiotherapists and medicines, during lifetime horizon. Indirect costs of these patients were calculated under the assumption that they need 24/7 on-site care, usually by a family member (most of the time, the mother) who cannot produce income at home or paid a caregiver because this person must constantly take care of the patient with neuromotor disability. In either case, the salary was calculated as the mean salary in Colombia during 2019, which must be paid during lifetime horizon of patient. Finally, costs of productivity because neuromotor disability in children were calculated based on Colombia mean salary, assuming most people work between 25 and 65 years old (age of economic productivity)(41); and adjusted by the national unemployment rate during 2019(42).

The cost of the vaccines were taken from 2019 price list of the expanded immunization program published on PAHO website (43). PCV10 price was USD 12.85 per dose and PCV13 USD 14.50 per dose (43). The administration cost of USD 1 per dose was incorporated. The study assumed implementation of a 2+1 dose vaccination schedule at 3, 5 and 12 months of age.

\section{Choice of model}

A dynamic population model was designed to estimate costs and long-term health outcomes (Figure 1). Model structure was based on natural history of pneumococcal diseases (AOM, CAP and IPD) and their complications in infants and children (neuromotor disability and cochlear implant) considering the period PCV10 post-vaccinal. Clinical outcomes included on model were taken from PCVs clinical trials and after-effects were identified as most severe related with pneumococcal infections (44). Model includes vaccinated children ( $<5$ years) and unvaccinated adults ( $>18$ years), who benefit of PCVs herd effect (23).

Given that model time horizon is population lifetime, analysis was made with cycles based on annual probability of developing pneumococcal diseases. The model censures every year those patients who developed a pneumococcal disease or died and starts calculating the probabilities, and so on until lifetime horizon of each cohort.

Population were divided into three groups, according to risk level of becoming ill and dying from pneumococcal diseases: children vaccinated under 5 years of age; adults not vaccinated between 18-64 years; and unvaccinated adults > 64 years old. This economic model follows the newborns cohort born between 2019-2022 to expectancy of life of first cohort (80 years), which integrated the unvaccinated population in order to measure indirect vaccination effect.

\section{Assumptions}

This decision model considers following assumptions with respect to comparators:

- Herd effect on unvaccinated children and adults is same for both PCVs, although between the comparators, only PCV13 has shown protects unvaccinated individuals against vaccine-type pneumococcal infections across all age groups(45-48), but not PCV10 (49-51).

- The great migration of Venezuelans that Colombia has received in recent years (more than one million people in 2017) would imply a change in frequency distribution of country pneumococcal serotypes. Since SIREVA II records (15) do not identify patients' nationality, model assumes that such migration would not affect effectiveness of either of two PCVs.

- To adjust effectiveness of both vaccines according to distribution of pneumococcal serotypes in Colombia, this model just included country serotypes distribution between 2012 and 2016, because PCV10 entry in Colombia in 2011 could have changed frequency distribution of serotypes not included in it.

- Definition of older adult may differ among published studies, some include adults $>60$ years (29) or $>50$ years (52). Model assumes older adult definition as those $>65$ years of age, because most manuscripts have assumed such definition (28). For this reason, model has two different age groups to determine herd effect: 18-64 years and $>65$ years. 
- Life expectancy of 80 years in Colombia, which is slightly higher than what country currently has. Given that model evaluates a dynamic cohort of newborns until 2027, a life expectancy of 80 years was assumed because it can be achieved in next ten years, since it is a life expectancy like that currently reported by countries of the region, as Chile (53).

- Direct efficacy of vaccination is attenuated in both vaccines. This assumption is based on data from an exploratory analysis of The CommunityAcquired Pneumonia Immunization Trial in Adults (CAPiTA) trial (efficacy of PCV13 in older adults), in which they observed that efficacy had a 3 \% efficacy attenuation annual rate without statistical significance (54). For this reason, sensitivity analysis of this model will evaluate results with different values of effectiveness attenuation.

\section{Sensitivity Analyses}

Sensitivity analyses were performed to consider the uncertainties associated with different parameters, incidence rates, outcomes and costs. First, a sensitivity analysis was conducted to determine the influence of a specific parameter had on the incremental cost-effectiveness value, and the second, sensitivity analysis was a probabilistic analysis with the objective of captured the uncertainties of all parameters, it was conducted using second-order Monte Carlo simulations. The rates were adjusted to beta distributions and the costs to gamma distributions.

\section{Results}

\section{Base case analysis}

The vaccination in the first year of the vaccination with PCV13 compared with PCV10 could potentially prevent 2 cases of pneumococcal meningitis, 7 cases of pneumococcal sepsis, 1,083 cases of pneumonia, 897 cases of AOM, and 66 fatalities. Considering the herd effect for population non vaccinated, 41 episodes of pneumococcal meningitis, 777 cases of pneumococcal sepsis and 29,983 cases of pneumonia among adults could potentially be avoided. PCV13 yields 150,351 LYG in vaccinated cohorts (Table 4).

Regard to costs, the incremental cost of vaccination with PCV13 of full cohorts was estimated to USD 15,676 thousand, and due the reduced burden of pneumococcal disease, the potential cost saving for all cohorts were calculated to USD 169,261 thousand, direct costs were USD 125,025 thousand and indirect costs were USD 6,210 thousand. Taking herd effect into account, the cost saving for the cohorts were estimated to USD 53,702 thousand (Table $5)$.

As result, PCV13 shows as cost-saving strategy versus PCV10, with an incremental 149,186 LYG more than PCV10 and saves more than USD 169 million. PCV13 is a cost-saving strategy even when herd protection was not incorporated.

\section{Sensitivity results}

The determinist sensibility analysis showed that variation in probabilities, clinical outcomes and costs were relatively insensitive to changes in the parameters, the parameters with the greatest impact in this sensitivity analysis was the "cost of inpatient pneumonia in adults", which also reflects that PCV13 is a cost-saving strategy. None of the parameters change these results (Figure 2). In the probabilistic analysis, PCV13 will be cost-effective strategy in all thresholds compared with PCV10.

\section{Discussion}

PCV13 is a cost-saving strategy to avoid pneumococcal diseases in children and adults in Colombia compared to PCV10. The PCV13 inclusion would avoid an important number of pneumococcal OMA in infants and deaths, sepsis, consolidated pneumonia and LYG both adults and children, In terms of economical results, this vaccine would bring approximately USD 125 million of savings associated to care of health outcomes and 6 million indirect costs, the attention of the main sequels of pneumococcal disease during the horizon time of the study.

The main factor of these results is explained to difference of pneumococcal serotypes covered by both technologies: PCV10 contained less than $5 \%$ of the isolated serotypes of the cases of IPD reported by SIREVAll network and PCV13 almost $66 \%$ which affecting directly the effectiveness of both vaccines. The 19A and 3 serotypes entirely responsible for the difference observed in the vaccinal serotypes. Other study reported the positive trend of these serotypes in the pneumococcal disease over time as described in other study (17). Raw data comparing 19A and 3 serotypes distribution in 2011-2014 with 2015-2019 period reported a notable increase especially 19A serotype (30-44\% and 8-9\%, respectively)(14).

One report highlights the emergence of Streptococcus pneumoniae serotype 19A in the pediatric population in Bogotá, Colombia as the main cause of invasive pneumococcal disease after the introduction of PCV10 with important association to multidrug resistance, in patients with complete vaccination schedule with 3 doses of PCV10, suggesting that the emergence of serotype 19A occurs in vaccinated children and that cross protection of PCV10 against this serotype is not generated (55). An increasing burden of serotype $19 \mathrm{~A}$, is a substantial change in the epidemiological where product switching is recommended according with the WHO position paper. (19)

Other Latin-American countries have observed similar phenomenon, which non-vaccinal serotypes grow in isolated of IPD. A study carried up in Porto Alegre (Brazil) reported changes in percentage of 19A serotype from 1.2\% in 2011 to 18.5\% in 2014 (56). Other study in Brazil analyzing the laboratorybased surveillance reported the changes from 3.2\% in the period early-post -PCV10to 9.3\% five years after (57). In Chile, the 19A serotype went up the 
relative frequency in general population from $3.3 \%$ in pre- PCV10 to $12 \%$ in 2014 and $13 \%$ in 2015 . In infants the changes were more notables starting $5.8 \%$ reaching $25 \%$ and $19 \%$ in the 2014 and 2015 years (58).

This cost-effectiveness analysis has two features following the recommendation of the WHO (59): herd effect on adults and the indirect costs and loss of productivity of children who develop neuromotor disability. Tsaban and Ben-Shimol published a systematic review of the studies, based on which it was possible to calculate an indirect effect of PCV vaccination in adults which could vary according to uptake rates and time of PCV implementation (approximately 22\% (range: $0 \%-70 \%$ ) (28). This study found that the population most benefit of herd effect is the adults $>65$ years old. This means that an important proportion of population at risk of developing pneumococcal diseases, especially CAP, could be protected and reduce healthcare costs associated to attention of this disease.

Similarly, considering social perspective to make this economic evaluation requires us to calculate indirect costs of care for children who develop neuromotor disability as a complication of pneumococcal meningitis. These indirect costs are mainly produced by costs of the child's caregiver, which may be his mother or a third party (nurse) who cares the child. If caregiver is the mother, she must stop working to care for the child and therefore withdraws from labor market, in case the caregiver is a third party, the family must bear costs of this care. Likewise, costs of lost productivity of children with neuromotor disabilities should be included in economic evaluations of pneumococcal vaccines. Main raison d'être of the health systems is to avoid population poverty by two mechanisms: reduce out-of-pocket expenditure on health and offer good health to be economically productive. If a complication such as neuromotor disability cannot be avoided, child and his family will have greater economic vulnerability because both child and his mother or a family member cannot be economically productive for his family and for society.

Model has two main features, first a dynamic cohort and second the economic evaluation of herd effect in adults. An economic evaluation which incorporates dynamic cohort is closer to reality in mass vaccination technologies, allows to identify true economic outcomes of complications of low prevalence and high cost, usually minimized in fixed cohorts cause this kind of models evaluated for time frame the same cohort but during this time they would be different newborn cohorts are not be considered, each year new population is exposed to pneumococcal diseases so they would be vaccinated.

Studies monitoring the effect of vaccination in real life had identify the effects of herd immunity in PCVs (60), showed the extend vaccines benefits beyond the directly vaccinated population, which acts as a positive externality, decreases costs of healthcare and improves quality of life. Importance of herd effect lies in fact that pneumococcal diseases are common in older adults and their lethality is very high, in this way it is possible to indirectly prevent mortality from pneumococcal diseases. In addition, treatment of CAP and invasive pneumonia are expensive in older adults and complicate underlying diseases such as asthma or emphysema. Herd effects have been frequently quantified as part of economic evaluations of vaccines (61), the relevant results related with the incorporation of these indirect effects on unvaccinated people in the analysis is the decreased of Incremental Cost Effectiveness Ratio (ICER) and it has a minor impact on the ICER.

All these features allow to identify most of health outcomes in vaccinated and unvaccinated people and estimate in a better way total health resources used since vaccination programs are not just the vaccine acquisition costs, they are, as well, the potential additional disease burden over time and associated costs that may be incurred as a result of implementation. One of the limitations of this study was not included all the indirect effects, as the contributions to antimicrobial resistance, some studies have demonstrated that PCV13 prevents the transmission of S. pneumoniae (62-65), thereby reducing infections and limiting their transmission, vaccines allow providers to reduce the prescription of antibiotics (66). Therefore, there is a broader benefit of vaccination with PCVs, which, would be worth incorporating it into future studies. Other limitations is related to low precision and lack of statistical power of the PCV10 efficacy in Pneumococcal OMA due to the number of cases isolated (56 episodes) according to report of clinical trial, however, it is the currently available evidence considering that the isolation of causal agent in OMA is not a common practice.

The cost-effectiveness analysis in Colombia have become a key component of decisions on whether to adopt a public health policy, the previous Colombian specific cost-effectiveness analyses related to PCV have serve as input to the decision makers. One of them showed the cost effectiveness of PCV10 (4), with ICER of cost per LYG was US\$ 1,837 with PCV10 and US\$9,514 with PCV13 (67). However, up-date analysis that incorporates the serotypes during 2011 to 2014 period, found PCV13 was found to be good value for money and prevent additional burden of pneumococcal disease saving additional treatment costs, when compared with to keep-PCV10 in Colombia, with ICER per YLS was USD 2,319 for keep-PCV10 and USD 1,771 for switch-to PCV13 (17). These results showed ICER of PCV13 compared with PCV10 have changed and in this analysis PCV13 have showed a cost saving strategy. Although it was clear that these analyses are not comparable, because necessities used their own assumptions and estimates parameters, they are evidencing the changes in the in the results of ICERs, where PCV13 have becomes prefer option.

\section{Conclusions}

PCV13 is dominant versus PCV10 as a strategy to vaccinate newborns in Colombia because PCV13 avoided more IPD, consolidated CAP, pneumococcal AOM, complications, sequelae and deaths than PCV10. This is explained, mainly, because serotypes included in PCV13 represents $67 \%$ of those isolated in Colombia in children under 5 years between 2017-2019, while those included in PCV10 represents 5.2\% isolated in the same period.

\section{Declarations}

\section{Ethics approval and consent to participate}

Not applicable 
Consent for publication

Not applicable

Availability of data and materials

All data generated or analyzed during this study are included in this published article

\section{Competing interests}

The authors declare that they have no competing interests

\section{Funding}

This study was funded by Pfizer S.A.S.

\section{Authors' contributions}

$\mathrm{JO}$ and $\mathrm{AO}$ initiated and designed the study, acquired, analyzed and interpreted the data, and drafted the manuscript. All authors read and approved the final manuscript.

\section{Acknowledgements}

We thank the Health Management Organization which provided cost of medical care in its institution being fundamental component in this research

\section{List Of Abbreviations}




\begin{tabular}{|c|c|}
\hline AOM & Acute otitis media \\
\hline CAP & Community-acquired pneumonia \\
\hline CAPiTA & The Community-Acquired Pneumonia Immunization Trial in Adults \\
\hline CNS & Central nervous system \\
\hline DANE & National Administrative Department of Statistics \\
\hline DT & Diphtheria Toxoid \\
\hline GRADE & Grading of Recommendations Assessment, Development and Evaluation \\
\hline HMO & Health Maintenance Organization \\
\hline ICER & Incremental Cost Effectiveness Ratio \\
\hline INVIMA & National Institute for Surveillance on Drugs an Foods \\
\hline IPD & Invasive pneumococcal disease \\
\hline LYG & Life years gained \\
\hline NTHi & Non-typeable Haemophilus influenzae \\
\hline PAHO & Pan American Health Organization \\
\hline PAl & National Immunization Plan \\
\hline PCV10 & Pneumococcal 10-valent conjugated vaccine \\
\hline PCV13 & Pneumococcal 13-valent conjugated vaccine \\
\hline PCV7 & Pneumococcal conjugate 7-valent vaccine \\
\hline PCVs & Pneumococcal conjugate vaccines \\
\hline PD & Protein D \\
\hline RCT & Randomized controlled trial \\
\hline RIPs & Colombian Health Services Delivery Records \\
\hline S. pneumoniae & Streptococcus pneumoniae \\
\hline SIIPL-PCV & Serum Institute of India Pvt. Ltd.'s PCV candidate \\
\hline SIREVA II & Sistema de Redes de Vigilancia de Agentes Bacterianos Causantes de Meningitis y Neumonías \\
\hline SISMED & Drug Price Information System \\
\hline TT & Tetanus Toxoid \\
\hline USD & American dollars \\
\hline WHO & World Health Organization \\
\hline
\end{tabular}

\section{References}

1. Centers for Disease Control and Prevention. Pneumococcal Disease [Internet]. 2014. [Cited 2019 Dec 04] Available from: https://wwwnc.cdc.gov/travel/diseases/pneumococcal-disease-streptococcus-pneumoniae

2. Tan TQ. Pediatric invasive pneumococcal disease in the United States in the era of pneumococcal conjugate vaccines. Clin Microbiol Rev [Internet]. 2012 Jul [cited 2019 Oct 9];25(3):409-19. Available from: http://www.ncbi.nlm.nih.gov/pubmed/22763632

3. Lepoutre A, Varon E, Georges S, Gutmann L, Lévy-Bruhl D. Impact of infant pneumococcal vaccination on invasive pneumococcal diseases in France, 2001-2006. Eurosurveillance [Internet]. 2008 Aug 28 [cited 2019 Oct 9];13(35):18962. Available from: http://www.eurosurveillance.org/content/10.2807/ese.13.35.18962-en

4. Teixeira D, Guimarães N, pediatria HM-J de, 2019. Risk factors associated with the outcomes of pediatric bacterial meningitis: a systematic review. Elsevier [Internet]. [cited 2019 Oct 9]; Available from: https://www.sciencedirect.com/science/article/pii/S0021755719304413

5. Choi C. Bacterial Meningitis in Aging Adults. Clin Infect Dis [Internet]. 2001 Oct 15 [cited 2019 Oct 9];33(8):1380-5. Available from: https://academic.oup.com/cid/article-lookup/doi/10.1086/322688

6. Atkinson W. Epidemiology and prevention of vaccine-preventable diseases. 2006 [cited 2019 Oct 9]; Available from: https://books.google.es/books? $\mathrm{hl}=\mathrm{es} \& \mathrm{Ir}=\& \mathrm{id}=\mathrm{h} 9 \mathrm{BQG90D9e} 4 \mathrm{C} \& \mathrm{oi}=\mathrm{fnd} \& \mathrm{pg}=\mathrm{PR} 1 \& \mathrm{dq}=$ Epidemiology+and+Prevention+of+Vaccine-

Preventable+Diseases.+Atkinson,+W.,+Wolfe,+S.,+Hamborsky,+J.,+Mclntyre,+L.,+eds.+13th+ed.+Washington+DC:+Public+Health+Foundation,+2015.+ $(579+K B)$. Accessed+01/25/2018.\&ots=Ri0odvucBe\&sig=Bx3Dn1xEZKLXCf-oR4-NSSUe5xU 
7. Karppinen S, Teräsjärvi J, Auranen K, Schuez-Havupalo L, Siira L, He Q, et al. Acquisition and Transmission of Streptococcus pneumoniae Are Facilitated during Rhinovirus Infection in Families with Children. Am J Respir Crit Care Med [Internet]. 2017 Nov 1 [cited 2019 Oct 9];196(9):1172-80. Available from: http://www.atsjournals.org/doi/10.1164/rccm.201702-03570C

8. Henriques-Normark B, Tuomanen El. The pneumococcus: epidemiology, microbiology, and pathogenesis. Cold Spring Harb Perspect Med [Internet]. 2013 Jul 1 [cited 2019 Oct 9];3(7). Available from: http://www.ncbi.nlm.nih.gov/pubmed/23818515

9. Bluestone, C. D. (2000). Clinical course, complications and sequelae of acute otitis media. The Pediatric infectious disease journal, 19 (5), S37-S46. [Internet]. [cited 2019 Oct 9]; Available from: https://journals.Iww.com/pidj/fulltext/2000/05001/clinical_course,_complications_and_sequelae_of.7.aspx

10. World Health Organization. Global Vaccine Action Plan 2011-2020. Geneva. 2012;

11. Frank DeStefano; Dina Pfeifer; Hanna Nohynek. Safety profile of pneumococcal conjugate vaccines: systematic review of pre- and post-licensure data. Bulletin of the World Health Organization. 2008.

12. Albert B. Sabin, Organización Panamericana de la Salud, Plan para el desarrollo acelerado y la introducción de vacunas neumocócicas de GAVI en John Hopkins, Centros para el Control y la Prevención de Enfermedades.2. Instituto de Vac C para el C y la P de E. La carga de morbilidad de la enfermedad neumocócica y la rentabilidad de una vacuna antineumocócica en América Latina y el Caribe. Washington D.C. 2007;

13. María MS, García F, Uribe M. Evaluación económica de la inclusión de la vacuna antineumocócica en el Plan Ampliado de Inmunización. 2008 [cited 2019 Oct 9]; Available from: http://www.repository.fedesarrollo.org.co/handle/11445/892

14. Instituto Nacional de Salud. SIREVA II. Colombia. Informe vigilancia por laboratorio Streptococcus pneumoniae 2006-2018 [Internet]. 2019. Available from: https://www.ins.gov.co/buscador-eventos/Informacin de laboratorio/Vigilancia por laboratorio S. pneumoniae 2006-2018.pdf

15. Instituto Nacional de Salud. Grupo de Microbiología - Informe Nacional de Sireva II. Streptococcus pneumoniae - Distribución de los aislamientos invasores por año de vigilancia, departamento, grupos de edad, serotipos y sensibilidad antimicrobiana - Colombia 2019. [Cited 2020 May 20]; Available from: https://www.ins.gov.co/buscador-eventos/Informacin\%20de\%20laboratorio/Vigilancia-por-laboratorio-de-S-pneumoniae-en-Colombia2019.

16. Carrasquilla G, Porras A, Martinez S, Devadiga R TCA. Time -trend analysis of pneumococcal disease morbidity in children < 5 years of age after pneumococcal conjugate vaccine introduction in Colombia: An ecological study. 10th Int, Symp Pneumococci Pneumoccal Dis (ISPPD-10) Glasgow Scotland. 2016.

17. Castañeda-Orjuela C, De la Hoz-Restrepo F. How cost effective is switching universal vaccination from PCV10 to PCV13? A case study from a developing country. Vaccine [Internet]. 2018 Sep 11 [cited 2019 Oct 16];36(38):5766-73. Available from: http://www.ncbi.nlm.nih.gov/pubmed/30087049

18. Tregnaghi MW, Sáez-Llorens X, López P, Abate H, Smith E, Pósleman A, et al. Efficacy of Pneumococcal Nontypable Haemophilus influenzae Protein D Conjugate Vaccine (PHiD-CV) in Young Latin American Children: A Double-Blind Randomized Controlled Trial. Miller E, editor. PLoS Med [Internet]. 2014 Jun 3 [cited 2019 Oct 15];11(6): e1001657. Available from: http://www.ncbi.nlm.nih.gov/pubmed/24892763

19. World Health Organization. WHO Position Paper on Pneumococcal conjugate vaccines in infants and children under 5 years of age- February 2019 [Internet]. 2019 [cited 2020 Apr 20]. Available from: https://www.who.int/immunization/policy/position_papers/who_pp_pcv_2019_presentation.pdf? ua $=1$

20. Clarke E, Bashorun AO, Okoye M, Umesi A, Badjie Hydara M, Adigweme I, et al. Safety and immunogenicity of a novel 10-valent pneumococcal conjugate vaccine candidate in adults, toddlers, and infants in The Gambia-Results of a phase 1/2 randomized, double-blinded, controlled trial. Vaccine [Internet]. 2020 Jan 10 [cited 2020 Jun 24];38(2):399-410. Available from: https://pubmed.ncbi.nlm.nih.gov/31843266/

21. Ministerio de Salud y Protección Social. Nota técnica unidad de pago por capitación [Internet]. 2018. [Cited 2020 Feb 25]; Available from: https://www.minsalud.gov.co/salud/POS/Paginas/unidad-de-pago-por-capitacion-upc.aspx

22. Moreno M, Mejía A, Castro H. Manual para la elaboración de evaluaciones económicas en salud. 2014. [Cited 2019 Oct 10]. Available from: https://www.iets.org.co/Archivos/64/Manual_evaluacion_economica.pdf

23. Centers for Disease Control and Prevention (CDC). Direct and indirect effects of routine vaccination of children with 7-valent pneumococcal conjugate vaccine on incidence of invasive pneumococcal disease-United States, 1998-2003. MMWR Morb Mortal Wkly Rep [Internet]. 2005 Sep 16 [cited 2019 Oct 10];54(36):893-7. Available from: http://www.ncbi.nlm.nih.gov/pubmed/16163262

24. Atkins D, Briss PA, Eccles M, Flottorp S, Guyatt GH, Harbour RT, et al. Systems for grading the quality of evidence and the strength of recommendations II: Pilot study of a new system. BMC Health Serv Res [Internet]. 2005 Dec 23 [cited 2019 Oct 10];5(1):25. Available from: http://bmchealthservres.biomedcentral.com/articles/10.1186/1472-6963-5-25

25. Wasserman M, Sings HL, Jones D, Pugh S, Moffatt M, Farkouh R. Review of vaccine effectiveness assumptions used in economic evaluations of infant pneumococcal conjugate vaccine. Expert Rev Vaccines [Internet]. 2018 [cited 2020 Jul 22];17(1):71-8. Available from: https://www.tandfonline.com/action/journallnformation?journalCode=ierv20

26. Organización Panamericana de la Salud. Organización Mundial de la Salud. Indicadores básicos. Situación de Salud en las Américas 2017. OPS Washington DC. 2017; Available from: https://www.paho.org/relacsis/index.php/en/noticias/item/831-situacion-de-salud-en-las-americasindicadores-basicos-2017

27. Poehling KA, Talbot TR, Griffin MR, Craig AS, Whitney CG, Zell E, et al. Invasive Pneumococcal Disease Among Infants Before and After Introduction of Pneumococcal Conjugate Vaccine. JAMA [Internet]. 2006 Apr 12 [cited 2019 Oct 15];295(14):1668. Available from:

Page $9 / 14$ 
http://www.ncbi.nlm.nih.gov/pubmed/16609088

28. Tsaban G, Vaccine SB-S-, 2017 undefined. Indirect (herd) protection, following pneumococcal conjugated vaccines introduction: a systematic review of the literature. Elsevier [Internet]. [cited 2019 Oct 10]; Available from: https://www.sciencedirect.com/science/article/pii/S0264410X17305108

29. Black S, Shinefield H, Baxter R, Austrian R, Vaccine LE-, 2006 undefined. Impact of the use of heptavalent pneumococcal conjugate vaccine on disease epidemiology in children and adults. Elsevier [Internet]. [cited 2019 Oct 10]; Available from: https://www.sciencedirect.com/science/article/pii/S0264410X05001829

30. Hansen J, Black S, Shinefield H, Cherian T, Benson J, Fireman B, et al. Effectiveness of Heptavalent Pneumococcal Conjugate Vaccine in Children Younger Than 5 Years of Age for Prevention of Pneumonia. Pediatr Infect Dis J [Internet]. 2006 Sep [cited 2019 Oct 15];25(9):779-81. Available from: http://www.ncbi.nlm.nih.gov/pubmed/16940833

31. Departamento Administrativo Nacional de Estadística (DANE). Estimaciones y Proyecciones de Población. 2016. [cited 2017 Feb 5]. Available from: http://www.dane.gov.co/index.php/estadisticas-por-tema/demografia-y-poblacion/proyecciones-de-poblacion

32. Ministerio de Salud y Protección Social. Registro Individual de Prestaciones de Servicios de Salud - RIPS. [Internet]. Available from: https://www.minsalud.gov.co/proteccionsocial/Paginas/rips.aspx

33. Jaramillo-Bustamante JC, Marín-Agudelo A, Fernández-Laverde M, Bareño-Silva J. Epidemiology of sepsis in pediatric intensive care units. Pediatr Crit Care Med. 2012 Sep;13(5):501-8.

34. de Souza DC, Shieh HH, Barreira ER, Ventura AMC, Bousso A, Troster EJ. Epidemiology of Sepsis in Children Admitted to PICUs in South America*. Pediatr Crit Care Med. 2016 Aug;17(8):727-34.

35. Instituto Nacional de Salud. SIVIGILA [Internet]. 2020 [cited 2020 Feb 20]. Available from: https://www.ins.gov.co/buscador-eventos/Paginas/InfoEvento.aspx

36. National Collaborating Centre for Women's and Children's Health UK. Bacterial Meningitis and Meningococcal Septicaemia [Internet]. Bacterial Meningitis and Meningococcal Septicaemia: Management of Bacterial Meningitis and Meningococcal Septicaemia in Children and Young People Younger than 16 Years in Primary and Secondary Care. RCOG Press; 2010 [cited 2019 Oct 15]. Available from: http://www.ncbi.nlm.nih.gov/pubmed/22787688

37. Ferreira S, Sant'Anna CC, March M de FBP, Santos MARC, Cunha AJLA. Lethality by pneumonia and factors associated to death. J Pediatr (Rio J) [Internet]. 2014 Jan [cited 2019 Oct 15];90(1):92-7. Available from: http://www.ncbi.nlm.nih.gov/pubmed/24161238

38. Banco de la República de Colombia. Tasa Representativa del Mercado (TRM - Peso por dólar). 2019; [cited 2020 Jan 15]; Available from: https://www.banrep.gov.co/es/estadisticas/trm

39. Ministerio de Salud y Protección Social de Colombia. Sistema de información de precios de medicamentos -SISMED [Internet]. Available from: https://web.sispro.gov.co/WebPublico/Consultas/ConsultarCNPMCadenaComercializacionCircu2yPA_028_2_2.aspx

40. Peñaranda A, Mendieta JC, Perdomo JA, Aparicio ML, Marín LM, García JM, et al. Beneficios económicos del implante coclear para la hipoacusia sensorineural profunda. Rev Panam Salud Publica.2012;31(4)325-31. Available from: https://www.scielosp.org/scielo.php?pid=S102049892012000400009\&script=sci_arttext\&tlng=pt

41. Departamento Administrativo Nacional de Estadística (DANE). Boletín del Sistema Nacional de Información de Demanda Laboral - SINIDEL. Available from: https://www.dane.gov.co/index.php/estadisticas-por-tema/educacion/boletin-sinidel

42. Departamento Administrativo Nacional de Estadística (DANE). Gran encuesta integrada de hogares (GEIH) Mercado laboral. Available from: https://www.dane.gov.co/index.php/estadisticas-por-tema/mercado-laboral/empleo-y-desempleo/geih-historicos

43. Pan American Health Organization. Vaccination [Internet]. [cited 2019 Oct 10]. Available from: https://www.paho.org/hq/index.php? option=com_topics\&view=article\&id=341\&ltemid=40929\&lang=en

44. Gray BM, Dillon HC. Natural history of pneumococcal infections. Pediatr Infect Dis J [Internet]. 1989 Jan [cited 2019 Oct 10];8(1 Suppl):S23-5. Available from: http://www.ncbi.nlm.nih.gov/pubmed/2648290

45. Waight $\mathrm{P}$, Andrews N, ... SL-TL infectious, 2015 undefined. Effect of the 13-valent pneumococcal conjugate vaccine on invasive pneumococcal disease in England and Wales 4 years after its introduction: an. Elsevier [Internet]. [cited 2019 Oct 11]; Available from: https://www.sciencedirect.com/science/article/pii/S1473309915700447

46. Moore M, Link-Gelles R, ... WS-TLI, 2015 undefined. Effect of use of 13-valent pneumococcal conjugate vaccine in children on invasive pneumococcal disease in children and adults in the USA: analysis of multisite. Elsevier [Internet]. [cited 2019 Oct 11]; Available from:

https://www.sciencedirect.com/science/article/pii/S1473309914710813

47. Dagan R, Patterson S, ... CJ-C infectious, 2013 undefined. Comparative immunogenicity and efficacy of 13-valent and 7-valent pneumococcal conjugate vaccines in reducing nasopharyngeal colonization: a randomized. academic.oup.com [Internet]. [cited 2019 Oct 11]; Available from: https://academic.oup.com/cid/article-abstract/57/7/952/337783

Page $10 / 14$ 
48. Cohen R, Levy C, Bingen E, ... MK-TP, 2012 undefined. Impact of 13-valent pneumococcal conjugate vaccine on pneumococcal nasopharyngeal carriage in children with acute otitis media. journals.Iww.com [Internet]. [cited 2019 Oct 11]; Available from:

https://journals.Iww.com/pidj/Fulltext/2012/03000/The_Diagnosis_of_Tuberculosis.20.aspx

49. National Institute for Health and Welfare. Incidence of invasive pneumococcal disease in Finland [Internet]. 2016. Available from: https://www.thl.fi/en/web/thlfi-en/topics/information-packages/incidence-of-invasive-pneumococcal-disease-in-finland.

50. Bergh M van den, ... JS-Cl, 2012 undefined. Effects of the 10-Valent Pneumococcal Nontypeable Haemophilus influenzae Protein D-Conjugate Vaccine on Nasopharyngeal Bacterial Colonization in Young. academic.oup.com [Internet]. [cited 2019 Oct 11]; Available from: https://academic.oup.com/cid/article-abstract/56/3/e30/430087

51. Knol MJ, De Melker H, Sanders L van der EA. Incidence of invasive pneumococcal disease in the Netherlands up to four years after introduction of 10valent pneumococcal conjugate vaccination. Poster Present 10th Int Symp Pneumococci Pneumococcal Dis (ISPPD); June 29. 2016;(Glasgow, United Kingdom.).

52. Lexau C, Lynfield R, Danila R, Pilishvili T, Jama RF-, 2005 undefined. Changing epidemiology of invasive pneumococcal disease among older adults in the era of pediatric pneumococcal conjugate vaccine. jamanetwork.com [Internet]. [cited 2019 Oct 10]; Available from:

https://jamanetwork.com/journals/jama/article-abstract/201755

53. World Bank. Life expectancy at birth, total (years). 2015 [cited 2019 Oct 10]; Available from: https://scholar.google.es/scholar? $\mathrm{hl}=$ es\&as_sdt=0\%2C33\&q=Life+expectancy+at+birth\%2C+total+\%28years\%29\&btnG=

54. Werkhoven C Van, Huijts S., et al. 13-valent pneumococcal conjugate vaccine efficacy is declining with old age: results from an exploratory analysis of the CAPiTA trial. idsa.confex.com. 2014. [Internet]. [cited 2019 Oct 10]; Available from: https://idsa.confex.com/idsa/2014/webprogram/Handout/id2655/POSTER129_1099.pdf

55. Camacho Moreno G, Imbachi LF, Leal AL, Moreno VM, Patiño JA, Gutiérrez IF, et al. Emergence of Streptococcus pneumoniae serotype 19A (Spn19A) in the pediatric population in Bogotá, Colombia as the main cause of invasive pneumococcal disease after the introduction of PCV10 . Hum Vaccin Immunother. 2020 Feb 20;1-7.

56. Mott MP, Caierão J, Cunha GR, Del Maschi MM, Pizzutti K, D’Azevedo P, et al. Emergence of serotype 19A Streptococcus pneumoniae after PCV10 associated with a ST320 in adult population, in Porto Alegre, Brazil. Epidemiol Infect. 2019 Jan;147:e93. Available from: https://www.ncbi.nlm.nih.gov/pmc/articles/PMC6518833/pdf/S0950268819000013a.pdf

57. Brandileone M-CC, Almeida SCG, Minamisava R, Andrade A-L. Distribution of invasive Streptococcus pneumoniae serotypes before and 5 years after the introduction of 10-valent pneumococcal conjugate vaccine in Brazil. Vaccine. 2018 May;36(19):2559-66. Available from:

https://www.sciencedirect.com/science/article/pii/S0264410X18304791

58. Potin M, Fica A, Wilhem J, Cerda J, Contreras L, Escobar C, et al. Opinión del Comité Consultivo de Inmunizaciones Sociedad Chilena de Infectología: Vacuna neumocóccica conjugada en niños y la emergencia de serotipo 19A. Rev Chil infectología. 2016 Jun;33(3):304-6. Available from: https://scielo.conicyt.cl/scielo.php?script=sci_arttext\&pid=S0716-10182016000300009

59. World Health Organization. WHO Guide on Standardization of Economic Evaluations of Immunization Programmes. No WHO/IVB/19.10. 2nd ed. Geneva; 2019. Available from: https://apps.who.int/iris/bitstream/handle/10665/329389/WHO-IVB-19.10-eng.pdf

60. Loo JD, Conklin L, Fleming-Dutra KE, Knoll MD, Park DE, Kirk J, et al. Systematic Review of the Indirect Effect of Pneumococcal Conjugate Vaccine Dosing Schedules on Pneumococcal Disease and Colonization. Pediatr Infect Dis J [Internet]. 2014 Jan [cited 2019 Oct 15];33:S161-71. Available from: http://content.wkhealth.com/linkback/openurl?sid=WKPTLP:landingpage\&an=00006454-201401002-00007

61. Nymark L, Sharma T, Miller A, Enemark U, Vaccine UG-, 2017 undefined. Inclusion of the value of herd immunity in economic evaluations of vaccines. A systematic review of methods used. Elsevier [Internet]. [cited 2019 Oct 17]; Available from:

https://www.sciencedirect.com/science/article/pii/S0264410X17314202

62. Angoulvant F, Cohen R, Doit C, Elbez A, Werner A, Béchet S, et al. Trends in antibiotic resistance of Streptococcus pneumoniae and Haemophilus influenzae isolated from nasopharyngeal flora in children with acute otitis media in France before and after 13 valent pneumococcal conjugate vaccine introduction. BMC Infect Dis [Internet]. 2015 Dec 21 [cited 2019 Oct 17];15(1):236. Available from: http://www.ncbi.nlm.nih.gov/pubmed/26093673

63. Imöhl M, Reinert RR, van der Linden M. Antibiotic susceptibility rates of invasive pneumococci before and after the introduction of pneumococcal conjugate vaccination in Germany. Int J Med Microbiol [Internet]. 2015 Oct [cited 2019 Oct 17];305(7):776-83. Available from:

http://www.ncbi.nlm.nih.gov/pubmed/26324014

64. Ben-Shimol S, Givon-Lavi N, Leibovitz E, Raiz S, Greenberg D, Dagan R. Near-Elimination of Otitis Media Caused by 13-Valent Pneumococcal Conjugate Vaccine (PCV) Serotypes in Southern Israel Shortly After Sequential Introduction of 7-Valent/13-Valent PCV. Clin Infect Dis [Internet]. 2014 Dec 15 [cited 2019 Oct 17];59(12):1724-32. Available from: http://www.ncbi.nlm.nih.gov/pubmed/25159581

65. Tomczyk S, Lynfield R, Schaffner W, Reingold A, Miller L, Petit S, et al. Prevention of Antibiotic-Nonsusceptible Invasive Pneumococcal Disease With the 13-Valent Pneumococcal Conjugate Vaccine. Clin Infect Dis [Internet]. 2016 May 1 [cited 2019 Oct 17];62(9):1119-25. Available from:

http://www.ncbi.nlm.nih.gov/pubmed/26908787

66. Grijalva CG, Nuorti JP, Griffin MR. Antibiotic Prescription Rates for Acute Respiratory Tract Infections in US Ambulatory Settings. JAMA [Internet]. 2009 Aug 19 [cited 2019 Oct 17];302(7):758. Available from: http://www.ncbi.nlm.nih.gov/pubmed/19690308

Page 11/14 
67. Castañeda-Orjuela C, Alvis-Guzmán N, Velandia-González M, De la Hoz-Restrepo F. Cost-effectiveness of pneumococcal conjugate vaccines of 7, 10, and 13 valences in Colombian children. Vaccine. 2012 Mar;30(11):1936-43.

\section{Tables}

Table 1

Pneumococcal conjugate vaccines efficacy

\begin{tabular}{|lllll|}
\hline Parameter & PCV13 & \multicolumn{3}{l|}{ PCV10 } \\
\hline & Value & Source & Value & Source \\
\hline Pneumococcal AOM & $40.4 \%$ & $(14,15,29)$ & $3.3 \%$ & $(14,15,18)$ \\
& $(7.9-53.4)$ & & $(0.8 \%-4.3)$ & \\
IPD & $60.7 \%$ & $(14,15,30)$ & 4.3 & $(14,15,29)$ \\
& $(51.6-62.3)$ & & $(3.6-4.9)$ & \\
\hline Radiographically confirmed pneumonia & $18.9 \%$ & $(14,15,29)$ & $1.1 \%$ & $(14,15,29)$ \\
& $(6.7-28.5)$ & & $(0.3-1.8)$ & \\
\hline
\end{tabular}

Table 2

Epidemiologic input parameters

\begin{tabular}{|c|c|c|}
\hline Parameter & Value & Source \\
\hline \multicolumn{3}{|l|}{$<5$ years } \\
\hline Sepsis due to $S$. pneumoniae (cases per 100.000) & $1.9 *$ & $(32-34)$ \\
\hline Meningitis due to $S$. pneumoniae (cases per 100.000) & 0.54 & $(35)$ \\
\hline Pneumonia consolidated in X-rays (cases per 100.000) & 90 & (18) \\
\hline AOM due to $S$. pneumoniae (cases per 100.000) & 36 & $(18)$ \\
\hline Neuromotor disability after meningitis due to pneumococcus & $22.00 \%$ & $(36)$ \\
\hline Cochlear implant in AOM by pneumococcus & $4.70 \%$ & $(36)$ \\
\hline Lethality due to meningitis & $34.57 \%$ & $(35)$ \\
\hline Lethality due to pneumonia of all etiologies & $5.80 \%$ & $(37)$ \\
\hline \multicolumn{3}{|l|}{$5-64$ years } \\
\hline Sepsis due to $S$. pneumoniae (cases per 100.000) & 3,7 & $(32)$ \\
\hline Meningitis due to $S$. pneumoniae (cases per 100.000) & 0,8 & $(32)$ \\
\hline Pneumonia consolidated in X-rays (cases per 100.000) & 204 & $(32)$ \\
\hline \multicolumn{3}{|l|}{65 years } \\
\hline Sepsis due to $S$. pneumoniae (cases per 100.000) & 32 & $(32)$ \\
\hline Meningitis due to $S$. pneumoniae (cases per 100.000) & 1,7 & $(32)$ \\
\hline Pneumonia consolidated in X-rays (cases per 100.000) & 1235 & $(32)$ \\
\hline
\end{tabular}


Table 3

Costs of pneumococcal diseases by groups of age, 2019

\begin{tabular}{|llllll|}
\hline Age groups (age) & Mean & SD & Minimum & Maximum & Source \\
\hline $0-17$ & & & & & \\
\hline Sepsis & 6,584 & 12,794 & 235 & 84,013 & Colombian HMO \\
\hline Meningitis & 9,319 & 11,127 & 937 & 44,115 & Colombian HMO \\
\hline Pneumonia consolidated in X-rays & 1,490 & 2,813 & 246 & 32,800 & Colombian HMO \\
\hline Pneumococcal AOM & 32 & 6 & 29 & 36 & Colombia HMO \\
\hline Neuromotor disability (direct costs) & 24,426 & & 21,983 & 26,868 & Assumption \\
\hline Cochlear implant & 73,608 & & 66,247 & 80,969 & (40) \\
\hline Neuromotor disability (indirect costs) & 265,262 & & 238,735 & 291,788 & Assumption \\
\hline Productivity loss costs & 132,631 & & 119,368 & 145,894 & Assumption \\
\hline 18-80 & & & & & \\
\hline Outpatient pneumonia & 55 & 11 & 49 & 60 & Colombia HMO \\
\hline Inpatient pneumonia & 1,627 & 5,207 & 25 & 112,962 & Colombian HMO \\
\hline Sepsis & 5,903 & 9,640 & 40 & 77,971 & Colombian HMO \\
\hline Meningitis & 7,911 & 8,507 & 264 & 28,798 & Colombian HMO \\
\hline
\end{tabular}

Table 4

Estimated pneumococcal disease cases prevented

\begin{tabular}{|c|c|c|c|}
\hline & PCV10 & PCV13 & Difference \\
\hline \multicolumn{4}{|l|}{ Vaccinated cohorts } \\
\hline Sepsis & 8,912 & 7,707 & 1,205 \\
\hline Meningitis & 1,395 & 1,198 & 197 \\
\hline Pneumonia & 599,210 & 538,936 & 60,274 \\
\hline AOM & 72,757 & 46,138 & 26,619 \\
\hline Neurologic disability & 201 & 172 & 28 \\
\hline Cochlear implants & 3,420 & 2,168 & 1,251 \\
\hline Deaths & 38,317 & 34,337 & 3,980 \\
\hline LYG & 805,370 & 954,556 & 149,186 \\
\hline \multicolumn{4}{|c|}{ Non vaccinated cohorts } \\
\hline Sepsis & 9,378 & 8,601 & 777 \\
\hline Meningitis & 1,158 & 1,117 & 41 \\
\hline Pneumonia & 218,071 & 188,087 & 29,983 \\
\hline
\end{tabular}

Table 5

Estimated costs (in USD thousand)

\begin{tabular}{|llll|}
\hline & PCV10 & PCV13 & Difference \\
\hline Vaccinated cohorts & & & \\
\hline Vaccination costs & 131,579 & 147,255 & 15,676 \\
\hline Direct medical costs & 495,396 & 370,372 & 125,025 \\
\hline Indirect medical costs & 21,072 & 14,862 & 6,210 \\
\hline Non vaccinated cohorts & & & \\
\hline Direct medical costs & 430,782 & 377,080 & 53,702 \\
\hline
\end{tabular}




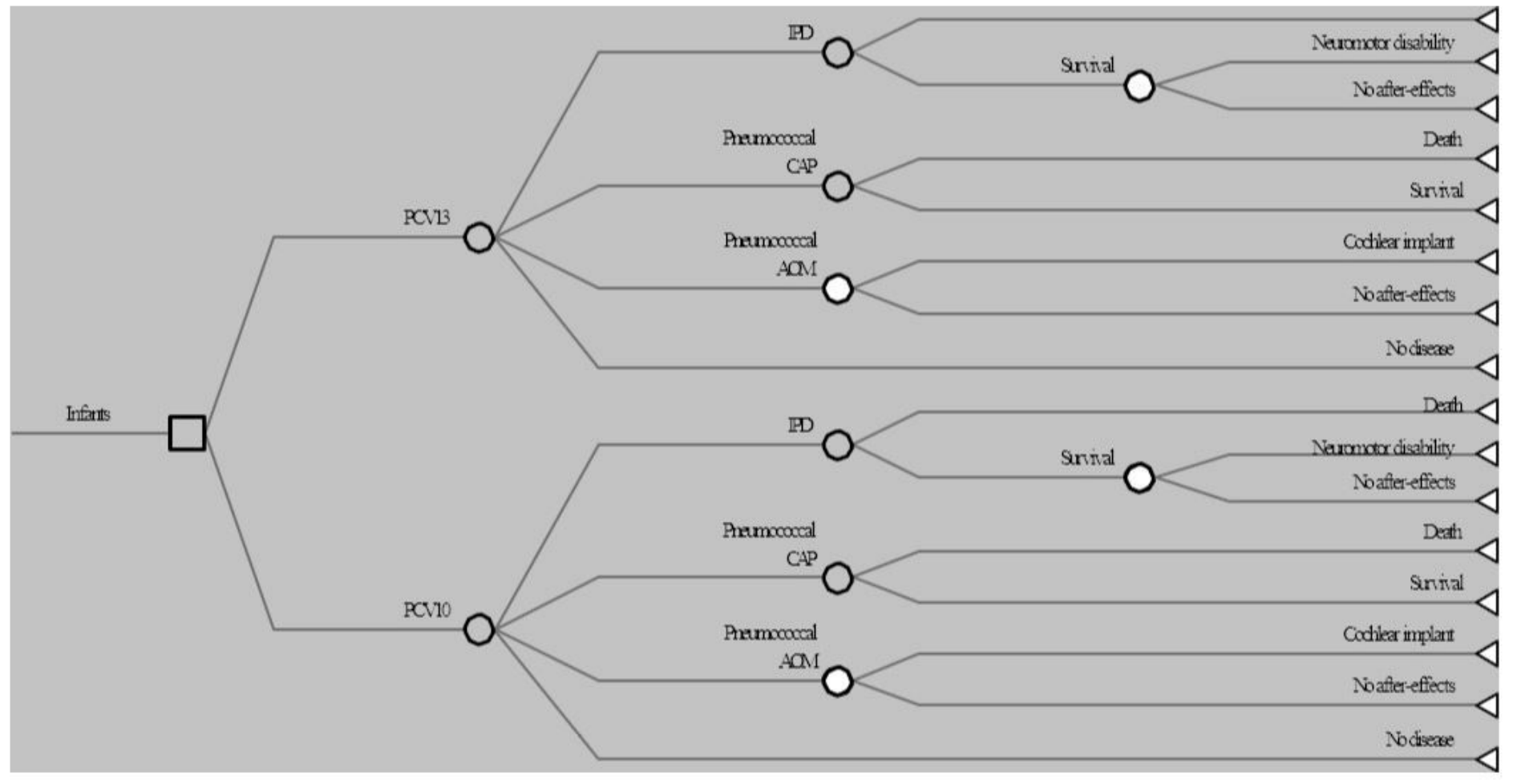

Figure 1

Figure 1

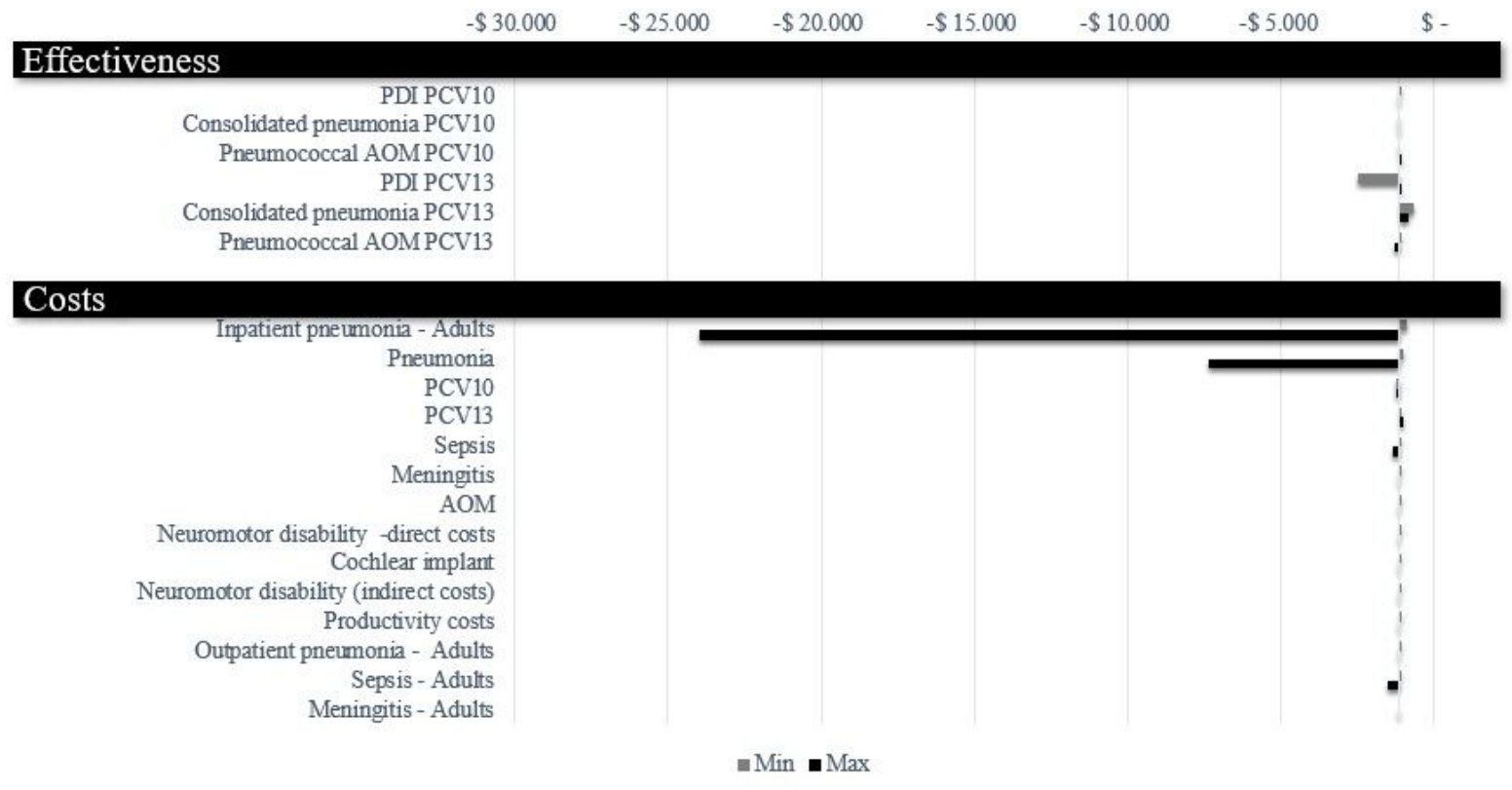

Figure 2

Figure 2 